\title{
Electro-Acupuncture Efficacy on Pain Control after Mandibular Third Molar Surgery
}

\author{
Marconi Gonzaga TAVARES ${ }^{1}$ \\ Ana Paula MACHADO ${ }^{1}$ \\ Breno Gutierrez MOTTA ${ }^{1}$ \\ Maria Cristina BORSATTO² \\ Adalberto Luiz ROSA ${ }^{1}$ \\ Samuel Porfírio XAVIER ${ }^{1}$ \\ ${ }^{1}$ Department of Oral Maxillofacial Surgery and Periodontology, School of Dentistry of Ribeirão Preto, \\ University of Sao Paulo, Ribeirão Preto, SP, Brazil \\ ${ }^{2}$ Department of Pediatric Clinic, Preventive and Community Dentistry, School of Dentistry of Ribeirão Preto, \\ University of Sao Paulo, Ribeirão Preto, SP, Brazil
}

\begin{abstract}
The aim of this study was to evaluate the efficacy of electro-acupuncture (EAC) on postoperative pain control after mandibular third molar surgery. Twenty four young patients (12 male and 12 female) with symmetrically impacted mandibular third molars were selected. Each patient was submitted to two separate surgical procedures under local anesthesia. At one side, extraction was carried out employing both prior (24h) and immediately postoperative application of EAC, while on the contralateral side surgery was carried out without any treatment. EAC was applied on 6 bilateral systemic and 2 auricular points with a WQ10Dl appliance using 40-60Hz frequency for $20 \mathrm{~min}$ and individually adjusted intensity. Postoperative pain intensity was rated on a $100 \mathrm{~mm}$ visual analog scale (VAS) between 2 and $72 \mathrm{~h}$ and recording the amount of analgesics intake after surgery. Statistical analysis was performed using the Wilcoxon test. Postoperative pain VAS scores were significantly lower for the EAC group $(p<0.05)$ and analgesic intake decreased $(p<0.05)$ for all evaluated periods $(\mathrm{p}<0.05)$. Under the tested conditions EAC therapy is efficient was proved controlling postoperative pain following mandibular third molar surgical removal.
\end{abstract}

Key Words: electro-acupuncture, oral surgery, mandibular third molars, postoperative pain.

\section{INTRODUCTION}

Surgical removal of impacted mandibular third molars is one of the routine aspects of oral-maxillofacial surgery and is well known to result in morbidity including pain, swelling and trismus, associated to intense inflammatory response.

Third molar surgical extractions are pain models to evaluate analgesic efficacy due to the following characteristics: surgeries are elective; patients are routinely ambulatory and healthy with few confounding disease states; procedures are consistent and postoperative pain typically begins within 1 to $3 \mathrm{~h}$ after surgery and ranges from moderate to severe intensity, requiring use of analgesics (1).
Postoperative pain and swelling are usually controlled by administering drugs to patients before and after surgery in order to decrease the natural inflammatory response. Nonsteroid antiinflammatory drugs (NSAIDs) are the most commonly used drugs due to their inhibitory effect on the cyclooxygenase enzyme. However, nonselective NSAIDs are associated to increased surgical bleeding and important gastrointestinal (GI) effects, including ulceration. Cyclooxygenase-2 (COX-2) selective inhibitors effectively treat pain and inflammation in both acute and chronic conditions, while presenting minimum inhibitory effect on COX-1 at full therapeutic doses (2). Because of this selective inhibition, side effects are minimal. On the other hand, higher costs might decrease its use. 
The advantages of EAC as an analgesic therapy applicable to oral surgery have been reported $(3,4)$. Simmons and Oleson (5) verified increased dental pain threshold after auricular EAC application. Scientific interest promoted it to a supplementary therapy for oral pain control with no significant side effects (6).

Tsui and Leung (7) showed that EAC is superior to conventional (manual) acupuncture on pain relief while treating patients with chronic tennis elbow. Kim et al. (8), evaluating analgesic effects in rats concluded that manipulation (rotation or alteration in the depth of needle insertion) combined with EAC produces a more potent antinociception as compared to EAC only.

Conversely, there are studies showing increase, decrease or statistical similarity in postoperative pain after third molar surgeries. Ekblom et al. (9) concluded that acupuncture application before or immediately after surgical removal of impacted mandibular third molars raised the pain levels during postoperative period. However, acupuncture treatment was applied either before or after surgical procedure and electrical stimulation was not used in this study.

Lao et al. (10) demonstrated the effectiveness of acupuncture as a supplementary therapy for pain control after impacted third molar surgery and lack of relationship between pain scores and patient expectation. This study was also carried out without electrical stimulation at the acupunctured points. A minimum of 4 points were used as a protocol ipsilaterally to remove a partially impacted lower tooth.

Evaluation of analgesic effects of EAC on postoperative third molar surgery was performed by Kitade and Ohyabu (11). They found either an increase tendency, though not significant, or a decrease in pain measurements, depending on the difficulty of tooth removal. They also concluded that application of EAC after and before surgery had a slightly more marked analgesic effect than only postoperative EAC treatment. Information about the frequency of VAS periods and analgesic administration is missing. Only four acupuncture points were stimulated ipsilaterally or on both sides and the frequency used for stimulation $(3 \mathrm{~Hz})$, was not within the ideal range $(40-60 \mathrm{~Hz})$.

Due to missing data and different protocols used in previous studies with contradicting results and lack of consistency in evaluating EAC efficacy on pain control after impacted lower third molar surgery, new studies are required to address this point unequivocally.
The aim of this study was to evaluate the efficacy of EAC on postoperative pain control after mandibular third molar surgery.

\section{MATERIAL AND METHODS}

\section{Patient Selection}

This study was approved by the local ethics committee and all patients signed an informed consent form. A total of 24 patients (12 male and 12 female) were selected by the following inclusion criteria: ASA grade 1 , age between 18 and 25 years and bilateral symmetrically impacted mandibular third molars advised for extraction. Orthopantomographic radiograms were obtained to ensure similarity of the impaction type. Patient exclusion criteria were self-prescription of any medication that could alter pain evaluation, such as analgesic or antiinflammatory drugs within $24 \mathrm{~h}$ of surgery or during the postoperative measurements; pregnant women; history of allergy to paracetamol or local anesthetics; history of prior treatment with EAC.

Before the operative procedures, all patients were acquainted with the visual analog pain scoring method and analgesic drug administration.

\section{Electro-Acupuncture Treatment}

One single experienced acupuncturist undertook the EAC treatment. After cleaning with 70\% alcohol, disposable acupuncture KS (Korean Style) needles (Suzhou Huanqiu Acupuncture Medical Appliance Co. Ltd., 218, China) were inserted up to specific depth according to each point. The exact depth of each systemic point was determined either when "Qi" induced response was reported by the patient or the maximum advised depth was reached. Lao et al. (10) defined "Qi" as a sensation of soreness, numbness or distention at the acupuncture point. Insertion into auricular points was more superficial, as the cartilage was reached but not surpassed. Needles were inserted bilaterally into systemic points and ipsilaterally to the extraction side into auricular points.

A total of 14 needles were used on each patient. Twelve needles ( $0.25 \mathrm{~mm}$ diameter $\mathrm{x} 30 \mathrm{~mm}$ long) were applied at systemic points and 2 needles $(0.17 \mathrm{~mm}$ diameter x $17 \mathrm{~mm}$ long) at auricular points.

Needles remained in place for $20 \mathrm{~min}$ and were 
then removed. All needles were twisted every $10 \mathrm{~min}$ : at the beginning of the procedure, after 10 min of treatment and at the end. A Multiple Electronic Acupunctoscope (MEA) WQ-IOD1 model (Beijing Hoidian District Danghua Electronic Instrument Factory, China) was used for electrical stimulation on systemic points only. The ideal frequency ranges from 40 to $60 \mathrm{~Hz}$ (12). Needles were then stimulated electrically at $50 \mathrm{~Hz}$ and zero intensity. The intensity was then slowly raised until reaching maximum level based on the patient's comfort.

Acupuncture points were established according to specific literature, which demonstrates direct relationship to impacted lower third molar surgery. These points were chosen based on "Point Function" theory, which determines that each point has its own function (13). This theory allowed for a specific and reproducible combination of points that was used for each patient.

The following acupuncture points were used in each patient: Hegu (IG 4), Taichong (F3), Neiting (E44), Xuanzhong (VB39); Ermen (TA21); Kunlun (B60); Shenmen and "Ponto Total".

\section{Surgical Procedure}

All patients were operated by the same surgeon under local anesthesia, between 8:00 and 12:00 am and using standard oral surgical procedures. The extractions were done at two different occasions: the second operation was carried out 4 weeks after the first.

On one side, extraction was carried out using both prior (24 h) and immediately postoperative application of EAC (EAC), while on the contralateral side surgery was done with no treatment (control). Treatment modality was randomly selected for each patient.

$2 \%$ mepivacaine with 1:100,000 nor-epinephrine (Scandicaine 2\%, DFL, Rio de Janeiro, RJ, Brazil) was used for inferior alveolar and buccal nerve blocks. A standard incision was used, from the anterior border of the ramus to the distobuccal corner of second molar following the buccal gingival sulcus along the second molar. A vertical incision was made from the mesiobuccal corner of the second molar to the mucogingival line. After periosteal elevation, bone on buccal and distal sites was removed with round bur using abundant saline irrigation. In all cases, the third molar was split using a tungsten fissure bur and a straight elevator. The tooth was carefully removed in several pieces. The alveolus was inspected and gently curetted for granulation tissue followed by abundant saline irrigation. Closure was done with $34 / 0$ silk sutures. A gauze pack was pressed against the surgical site and the patient was instructed to bite on it for $30 \mathrm{~min}$.

The duration of operation was recorded as the period between the first incision and the last suture. Patients were given routine postoperative instructions, and sutures removed 7 days after surgery.

\section{Data}

Pain scores were obtained using a $100 \mathrm{~mm}$ visual analog scale (VAS: $0=$ no pain; $100=$ worst pain possible), which is a reliable and sensitive method to measure pain. In the first $12 \mathrm{~h}$, the patients were instructed to write down pain level every $2 \mathrm{~h}$. Then, pain was evaluated every $6 \mathrm{~h}$ until 72 postoperative $h$.

Analgesic (paracetamol $750 \mathrm{mg}$ ) intake was recorded for the first $72 \mathrm{~h}$ after surgery by the total amount of consumed tablets and administration time. The advised dose was 1 tablet every $6 \mathrm{~h}$ for the first 3 days after surgical procedure, in case of pain.

Statistical analysis was performed by Wilcoxon test. Data were statistically significant when $\mathrm{p}<0.05$.

\section{RESULTS}

Six patients were excluded due to intake of nonprescribed drugs or inappropriate filling out the forms. These subjects were replaced by other patients. 24 patients returned their forms correctly filled. No patient had any serious complication or related any side effect.

Both treatments were comparable for their operative characteristics. An equal number of male and female patients were enrolled in this study, without ethnic specification. The mean age of the subjects was 20.42 years ( $\pm \mathrm{sd}=1.44$ years, range $=18$ to 24 years ). According to Winter's classification of tooth inclination, the obtained data were: 18 vertical, 14 mesioangular, 8 horizontal and 8 distoangular.

There was no significant difference between both operations, as regards duration of surgery and the amount of local anesthetic administered.

Five patients under EAC treatment and 2 control patients did not take analgesics in the postoperative period. Twelve subjects under control treatment took at least one tablet in the first $2 \mathrm{~h}$ after surgery, while on EAC group only 7 patients took analgesics in this period. 
The VAS of pain was significantly lower for the EAC group for all times ( $<<0.05)$ (Fig. 1).

There was significant difference between the two treatments in postoperative analgesics consumption $(\mathrm{p}<0.05)$ (Fig. 2). Subjects in the control group (total intake 110 tablets) had a mean of 4.58 tablets ( \pm $\mathrm{sd}=3.87$ ). Subjects in the EAC group (total intake 46 tablets) had a mean of 1.92 tablets $( \pm \mathrm{sd}=2.04)$.

\section{DISCUSSION}

Lao et al. (6) pointed out the increased acceptance of acupuncture by the western culture, but an appropriate methodology to scientifically evaluate the effect of acupuncture remains undefined. These authors (6) published a well controlled study on the efficiency and safety of acupuncture using acceptable methods and pain models.

This study employed a method where one side of each patient was included in the control group and the other side (randomly selected) was in the EAC group. In this EAC model, the patient becomes his/her own control, in order to eliminate any individual response differences towards acupuncture treatment. In addition, only one surgeon, auxiliary and acupuncturist were chosen; one single local anesthesia was established to avoid any anesthetic drug interference and no other tooth was extracted in the same procedure.

A major problem with EAC research is the difficulty in designing appropriate control groups (6). Mock transcutaneous nerve stimulation and placebo EAC could be used, but none of them was considered

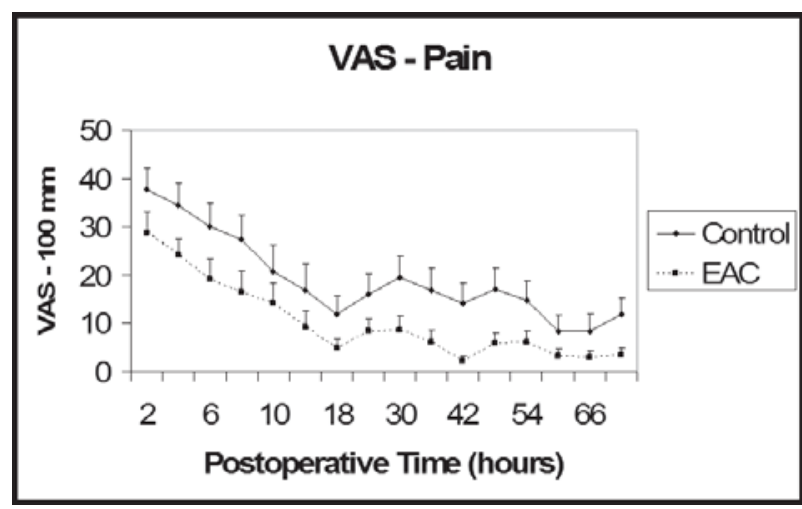

Figure 1. Visual analog scale (VAS) for pain measurement. EAC group scores were significantly different for all evaluated periods $(\mathrm{p}<0.05)$. appropriate (6). An investigation into placebo acupuncture (14) failed to show any significant differences between "true acupuncture" and placebo. In view of this, no placebo control was used in this experiment.

Studies have shown that EAC does reduce postoperative pain (general or oral) (6). Lin et al. (15) found that preoperative EAC treatment can reduce postoperative analgesic requirements and associated side effects after abdominal surgery. Sim et al. (16) concluded that preoperative EAC reduces intra-operative analgesic intake after gynecologic lower abdominal surgery.

In oral surgery, controversial results can be found. Thomas and Thomas (17) reported that prophylactic acupuncture for tooth extraction enhanced postoperative pain. Kitade and Ohyabu (11) found a similar pattern on "easy to extract" teeth, though not significant when compared to a control group. But most of the reports show that EAC tends to reduce postoperative pain and analgesic consumption $(6,11)$.

Steroids can decrease pain and edema scores after third molar surgery. Since acupuncture is known to increase blood cortisol levels after application (18), it may diminish pain and swelling.

In the control group, analgesic intake was more than twice the amount in the EAC group (control/EAC $=110 / 46$ tablets) and almost twice as many patients in the control group had the first tablet in the subsequent $2 \mathrm{~h}$ after surgery, compared to the EAC group (control/ $\mathrm{EAC}=12 / 7$ individuals). Thus, EAC treatment significantly reduced both total amount of analgesics taken and number of patients who required the drug earlier.

In this study, EAC significantly reduced pain

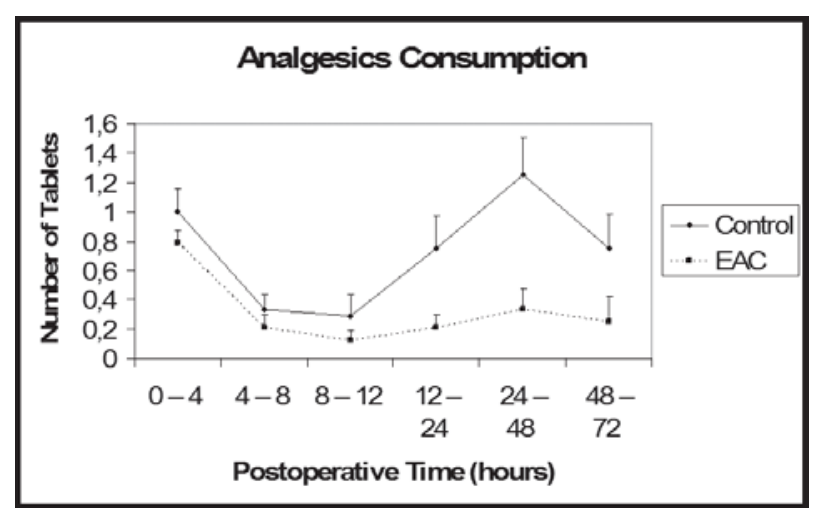

Figure 2. Analgesic consumption. Number of tablets of paracetamol $750 \mathrm{mg}$. EAC group intake of tablets was significantly different for all evaluated periods ( $<<0.05)$. 
scores for all evaluated times $(\mathrm{p}<0.05)$. An estimated $63.5 \%$ of the patients experienced severe pain at some time during the first day after surgery. According to Bjornsson et al. (19), pain is most severe in the first $6 \mathrm{~h}$ after surgery. EAC treatment significantly reduced pain in the first $6 \mathrm{~h}$ after surgery. Two hours after surgery, the decrease in VAS pain score was from $37.63 \mathrm{~mm}$ to $28.71 \mathrm{~mm}$, on the average. After $4 \mathrm{~h}$, it decreased from a mean of $34.33 \mathrm{~mm}$ to $24.04 \mathrm{~mm}$. After $6 \mathrm{~h}$, from 30.08 $\mathrm{mm}$ to $19.04 \mathrm{~mm}$ on the average. These differences represent, respectively, a $23.70 \%, 30 \%$ and $36.7 \%$ reduction, which is clinically significant according to Campbell and Patterson (20).

In conclusion, this study provides a viable and simple method for scientific evaluation of EAC and its outcomes on pain measurements, without a placebo control group. EAC did reduce analgesic intake and was more effective on pain control than the control. Thus, it can be widely used as an adjunctive therapy for pain control after third molar surgery, without any associated side effects to it.

\section{RESUMO}

O objetivo desta pesquisa foi verificar a eficácia da aplicação de eletro-acupuntura (EAC) na redução da dor após a exodontia de terceiros molares inferiores inclusos. Foram selecionados 24 pacientes jovens (12 homens e 12 mulheres) com inclusão bilateral de terceiros molares inferiores em posição similar. Cada paciente foi submetido aleatoriamente a dois procedimentos cirúrgicos em dias diferentes: em um deles o dente foi extraído com uma sessão pré-operatória (24 h) e uma pós-operatória imediata de EAC enquanto no outro a extração foi feita sem EAC. A EAC foi aplicada em 6 pontos sistêmicos bilaterais e 2 auriculares com um aparelho WQ10D1 utilizando freqüência de $40-60 \mathrm{~Hz}$ por $20 \mathrm{~min}$ com intensidade ajustada individualmente. A dor foi avaliada desde $2 \mathrm{~h}$ até $72 \mathrm{~h}$ pós-operatórias utilizando a escala visual análoga (EVA) de $100 \mathrm{~mm}$ e pelo consumo de analgésicos. Os dados foram comparados pelo teste de Wilcoxon. Os escores de dor da EVA foram significantemente menores para o tratamento com EAC $(p<0,05)$ enquanto o consumo de analgésico diminuiu $(p<0,05)$ em todos os períodos $(p<0,05)$. O tratamento com EAC mostrou-se eficiente no controle da dor pós-operatória após cirurgia de extração de terceiros molares inferiores inclusos.

\section{ACKNOWLEDGEMENTS}

The authors acknowledge financial support from FAPESP

\section{REFERENCES}

1. Cooper SA. Models for clinical assessment of oral analgesics. Am J Med 1983;14:24-29.
2. Everts B, Wahrborg P, Hedner T. COX-2-Specific inhibitors the emergence of a new class of analgesic and anti-inflammatory drugs. Clin Rheumatol 2000;19:331-343.

3. Kerr NW. Acupuncture for therapy and analgesia. Br Dent J 1973;6:201-204.

4. Sator-Katzenschlager SM and Michalek-Sauberer A. P-Stim auricular electroacupuncture stimulation device for pain relief. Expert Rev Med Devices 2007;4:23-32.

5. Simmons MS and Oleson TD. Auricular electrical stimulation and dental pain threshold. Anesth Prog 1993;40:14-19.

6. Lao L, Bergman S, Langerberg P, Wong RH, and Brian B. Efficacy of Chinese acupuncture on postoperative oral surgery pain. Oral Surg Oral Med Oral Pathol 1995;79:423-428.

7. Tsui $P$ and Leung MC. Comparison of the effectiveness between manual acupuncture and electro-acupuncture on patients with tennis elbow. Acupunct Electrother Res 2002;27:107-117.

8. Kim JH, Min BI, Schmidt D, Lee HJ, Park DS. The difference between electroacupuncture only and electroacupuncture with manipulation on analgesia in rats. Neurosci Lett 2000;279:149-152.

9. Ekblom A, Hansson P, Thomsson M, Thomas M. Increased postoperative pain and consumption of analgesics following acupuncture. Pain 1991;44:241-247.

10. Lao L, Bergman S, Hamilton GR, Langenberg P, Berman B. Evaluation of acupuncture for pain control after oral surgery. Arch Otolaryngol Head Neck Surg 1999;125:267-572.

11. Kitade $\mathrm{T}$ and Ohyabu H. Analgesic effects of acupuncture on pain after mandibular wisdom tooth extraction. Acupunct Electrother Res 2000;25:109-115.

12. Ribeiro DC. Dental acupuncture: A technique against pain. 1st ed. São Paulo: Ícone; 2002.

13. Maciocia, G. The fondations of chinese medicine: a comprehensive text for acupuncturists and herbalists. 2nd ed. Endinburg: Churchill Livingstone; 2005.

14. Michalek-Sauberer A, Heinzl H, Sator-Katzenschlager SM, Monov G, Knolle E, Kress HG. Perioperative auricular electroacupuncture has no effect on pain and analgesic consumption after third molar tooth extraction. Anesth Analg 2007;104:542-547.

15. Lin JG, Lo MW, Wen YR, Hsieh CL, Tsai SK, Sun WZ. The effect of high and low frequency electro-acupuncture in pain after lower abdominal surgery. Pain 2002;99:509-514.

16. Sim CK, Xu PC, Pua HL, Zang G, Lee TL. Efects of electroacupuncture on intraoperative and postoperative analgesic requirements. Acupunct Med 2002;20:56-65.

17. Thomas M, Thomas L. Does Acupuncture Work? Pain 1996;4:1-4.

18. Malizia E, Andreucci G, Paolucci D, Crescenzi F, Fabbri A, Fraioli F. Electroacupuncture and peripheral beta-endorphin and ACTH levels. Lancet 1979;2:535-536.

19. Bjornsson GA, Haanaes HR, Skoglund LA. A randomized, double-blind crossover trial of paracetamol $1000 \mathrm{mg}$ four times daily vs ibuprofen $600 \mathrm{mg}$ : effect on swelling and other postoperative events after third molar surgery. Br J Clin Pharmacol 2003;55:405-412.

20. Campbell WI and Patterson CC. Quantifying meaningful changes in pain. Anaesthesia 1998;53:121-125. 